Research Article

\title{
Evaluation of Ground Displacements Caused by Installing Jet Grouted Columns Using Machine Learning Methods
}

\author{
Zhi-Feng Wang ${ }^{10},{ }^{1}$ Xing-Bin Peng, ${ }^{1}$ Yong Liu, ${ }^{1}$ Wen-Chieh Cheng, ${ }^{2,3}$ Ya-Qiong Wang, \\ and Chao-Jun $\mathrm{Wu}^{4}$ \\ ${ }^{1}$ School of Highway, Chang'an University, Xi'an 710064, China \\ ${ }^{2}$ School of Civil Engineering, Xi'an University of Architecture and Technology, Xi'an 710055, China \\ ${ }^{3}$ Shaanxi Key Laboratory of Geotechnical and Underground Space Engineering (XAUAT), Xi'an 710055, China \\ ${ }^{4}$ Jinan Rail Transit Group Co. Ltd., Jinan 250101, China
}

Correspondence should be addressed to Zhi-Feng Wang; zhifeng.wang@chd.edu.cn

Received 27 May 2020; Revised 28 August 2020; Accepted 9 September 2020; Published 21 September 2020

Academic Editor: Zaobao Liu

Copyright (c) 2020 Zhi-Feng Wang et al. This is an open access article distributed under the Creative Commons Attribution License, which permits unrestricted use, distribution, and reproduction in any medium, provided the original work is properly cited.

\begin{abstract}
During the jet grouting process, large volumes of high pressurized fluids injected into the soils will cause significant ground displacements, which may bring harmful impacts on surrounding environment. Therefore, it is essential to provide an accurate estimation of the ground displacement in the design stage. Based on multiple nonlinear regression (MNLR) and support vector regression (SVR), the prediction approaches are established, respectively. The column radius $\left(R_{\mathrm{c}}\right)$, Young's modulus $(E)$, and distance from column center to target point $\left(L_{\mathrm{OA}}\right)$ are selected as the input parameters, while the displacement of target point A at the radial direction $\left(\delta_{\mathrm{A}}\right)$ is taken as the output parameter. Comparisons results on the prediction performance of ground displacements indicate that the MNLR-based approach has a better prediction effect. The design charts of the MNLR-based approach for predicting the ground displacement are created, which will be helpful for the practicing engineers to get a quick estimation.
\end{abstract}

\section{Introduction}

Jet grouting is invented based on the combination of hydraulic mining technology and grouting technique and has become one of the most popular ground improvement techniques in different construction fields for preventing geohazards in worldwide area [1-13]. Jet grouting is generally adopted to strengthen soft soil, such as ground improvement during deep excavations and tunnel construction [14-27] and reinforcement of embankment foundation [28-32]. Considering the types of fluids jetted from the nozzles, jet grouting systems can be divided into three categories [33-35]: (i) single fluid system (injection of high pressurized grout), (ii) double fluid systems (injection of high pressurized grout and compressed air), and (iii) triple fluid systems (injection of high pressurized water, compressed air, and low pressurized grout).
Because large volumes of high pressurized fluids are injected into the fine grained soils during the jet grouting process, it will cause significant ground displacements, which may bring harmful impacts on surrounding environment [36-38]. Therefore, it is essential to provide an accurate estimation of the ground displacement in the design stage. However, most researchers mainly focused on the prediction of diameter and strength of jet grouted columns [39-44], and there are few published literatures related to ground displacement caused by installation of jet grouted columns. Shen et al. [31] proposed a method to calculate the lateral displacements caused by installing vertical jet grouted columns in clayey soils based on the analytical solution developed by Verruijt [45]. Wang et al. [8] proposed an approach to estimate the ground displacements caused by installation of horizontal jet grouted columns. However, the practical engineers may lack relative mathematical 
knowledge, which may bring difficulty in the use of these existed methods and will limit their widespread application. Intelligent approaches based on machine learning methods are becoming more and more popular in the field of engineering geology and geotechnical engineering [46-50], which can effectively overcome the difficulties of arbitrary assumptions adopted in the current methods and increase the confidence in predictions. Multiple nonlinear regression (MNLR) is a form of regression analysis in which the dependent variables are modeled by a nonlinear function of the independent variables [51-53]. MNLR can establish the models to describe the arbitrary relationships between the independent variables and the dependent variables, and this is different from traditional multiple linear regression (MLR), which is only used to obtain linear models. It has been proven that MNLR is an efficient prediction tool by many researchers in different fields (e.g., the field of economics, marketing, and engineering). As a new and efficient intelligent approach, the support vector machine (SVM) was produced on the basis of machine learning theory to solve the classification problems at the initial stage, and then, it was developed to deal with the regression problems after introducing the $\varepsilon$-insensitive loss function. The support vector regression (SVR) technique is based on the structural risk minimization (SRM) principle, which is not only to minimize the error on the training data but also to minimize a bound on the generalization error of a model [54].

In this paper, in order to control and mitigate environmental impacts due to installation disturbance of jet grouting, the machine learning methods including MNLR and SVR are taken as an attempt to propose an approach to predict the ground displacements caused by installing jet grouted columns. A series of field data on ground displacements caused by installing jet grouted columns were collected to conduct the analysis by MNLR and SVR. Finally, the design charts to estimate ground displacement are created to make it easy to use the proposed approach in this study for practical engineers.

\section{Problem Description}

Jet grouting is invented based on the combination of hydraulic mining technology and grouting technique. In the construction of jet grouting, high pressurized fluids (grout or water) are jetted from the nozzles that are fixed on the rod and have small diameters into the ground. Then, the in situ soils below ground surface can be eroded by the high pressurized fluid jets, and an approximate cylindrical soilcement column will be formed by mixing the eroded soils with the injected grout. Figure 1 depicts the schematic view of ground displacements caused by installing a jet grouted column. As can be seen, the injection of large volumes of high pressurized fluids may cause an expansion effect in the internal stratum, which can induce movements in surroundings soil. Considering the jet grouting process, the factors influencing the ground displacements can be divided as follows: jetting parameters, soil properties, and distance to target point. Hence, the ground displacement caused by installing a jet grouted column can be expressed as a function of construction issues, soil properties, and distance to target point:

$$
\delta_{A}=f \text { (jetting parameters, soil properties, distance to target point), }
$$

where $\delta_{\mathrm{A}}$ is the displacement of point $\mathrm{A}$ at the radial direction, as shown in Figure 1.

For the effect of jetting parameters on ground displacements, the withdrawal rate of the rod, nozzle diameter, number of nozzles, flow rate of injected fluid, rotation speed of the rod, and jetting pressure of fluid are mainly concerned. The values of ground displacements will be larger if the higher values of jetting parameters are given when other conditions are the same. For the effect of soil properties on ground displacements, the soil strength and soil stiffness are mainly included. The values of ground displacements will be smaller if the higher values of jetting parameters are introduced when other conditions are the same. In this study, column radius $R_{\mathrm{c}}$, Young's modulus $E$, and distance from column center to target point $L_{\mathrm{OA}}$ are selected to represent the effects of jetting parameters, soil properties, and distance to target point on ground displacements, and their relationship can be expressed as follows:

$$
\delta_{A}=f\left(R_{c}, E, L_{\mathrm{OA}}\right),
$$

where $R_{\mathrm{c}}$ is the radius of jet grouted column, $E$ is Young's modulus of surrounding soils, and $L_{\mathrm{OA}}$ is the distance from column center (point O) to target point $A$, as shown in Figure 1. In summary, to yield an accuracy prediction of ground displacements caused by installing a jet grouted column, a reasonable approach using MNLR and SVR should be capable of considering these three parameters: column radius $R_{\mathrm{c}}$, Young's modulus $E$, and distance from column center to target point $L_{\mathrm{OA}}$.

\section{Data Preparation}

Based on the above thought on influencing factors, considering the column radius $R_{\mathrm{c}}$, Young's modulus $E$, and distance from column center to target point $L_{\mathrm{OA}}, 36 \mathrm{ex}-$ perimental data on ground displacements caused by installing a jet grouted column were collected from the published literature as regression data. Table 1 tabulates the collected experimental data on ground displacements caused by installing jet grouted columns. These field data were obtained from two case histories in two different soils. Figure 2 shows the geotechnical profile and soil properties for two case histories conducted in the soft clay and silty clay, respectively. As can be seen, the physical properties and mechanical parameters can be easily determined.

\section{Methodology}

4.1. Multiple Nonlinear Regression. Multiple nonlinear regression (MNLR) is a type of regression analysis in which the dependent variables are modeled by a nonlinear function of the independent variables. MNLR can establish the models to describe the arbitrary relationships between the 


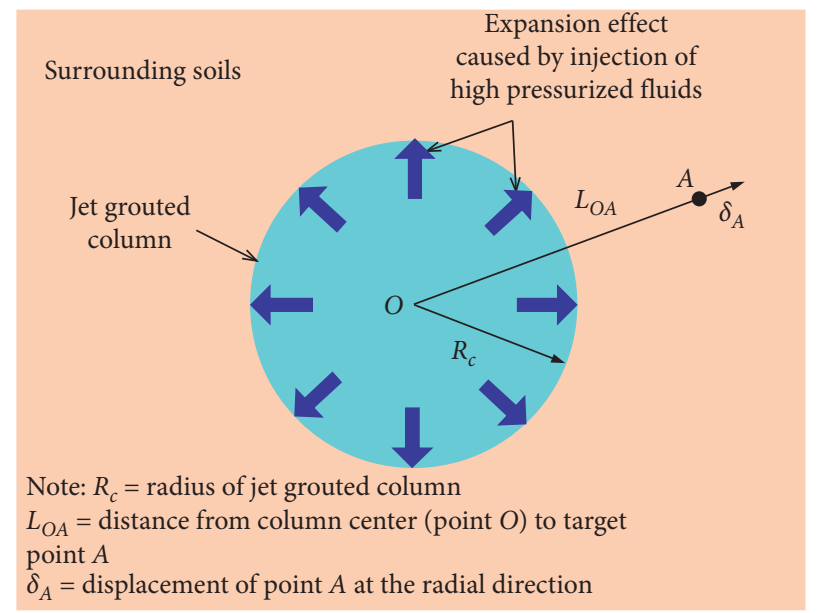

FIGURE 1: Schematic view of ground displacements caused by installing a jet grouted column.

TABLe 1: Data collected in this study.

\begin{tabular}{|c|c|c|c|c|c|c|}
\hline Data number & Soil types & $R_{\mathrm{c}}(\mathrm{m})$ & $E(\mathrm{kPa})$ & $L_{\mathrm{OA}}(\mathrm{m})$ & $\delta_{\mathrm{A}}(\mathrm{mm})$ & References \\
\hline 1 & Soft clay & 0.88 & 5370 & 7.4 & 31.2 & Shen et al. [31] \\
\hline 2 & Soft clay & 0.88 & 5882 & 7.4 & 26.9 & Shen et al. [31] \\
\hline 3 & Soft clay & 0.88 & 6393 & 7.4 & 22.7 & Shen et al. [31] \\
\hline 4 & Soft clay & 0.88 & 6905 & 7.4 & 17.7 & Shen et al. [31] \\
\hline 5 & Soft clay & 0.88 & 7416 & 7.4 & 14.2 & Shen et al. [31] \\
\hline 6 & Soft clay & 0.88 & 7927 & 7.4 & 9.6 & Shen et al. [31] \\
\hline 7 & Soft clay & 0.88 & 8439 & 7.4 & 6.5 & Shen et al. [31] \\
\hline 8 & Soft clay & 0.88 & 14321 & 7.4 & 3.7 & Shen et al. [31] \\
\hline 9 & Soft clay & 0.88 & 15139 & 7.4 & 2.3 & Shen et al. [31] \\
\hline 10 & Soft clay & 0.88 & 15957 & 7.4 & 1.5 & Shen et al. [31] \\
\hline 11 & Silty clay & 0.5 & 2500 & 6.5 & 44.2 & Wang et al. [8] \\
\hline 12 & Silty clay & 0.5 & 2500 & 6.5 & 47.4 & Wang et al. [8] \\
\hline 13 & Silty clay & 0.5 & 5000 & 6.1 & 15.1 & Wang et al. [8] \\
\hline 14 & Silty clay & 0.5 & 5000 & 5.8 & 13.9 & Wang et al. [8] \\
\hline 15 & Silty clay & 0.5 & 5000 & 5.6 & 14.6 & Wang et al. [8] \\
\hline 16 & Silty clay & 0.5 & 5000 & 5.4 & 15.1 & Wang et al. [8] \\
\hline 17 & Silty clay & 0.5 & 5000 & 5.2 & 14.9 & Wang et al. [8] \\
\hline 18 & Silty clay & 0.5 & 5000 & 5.1 & 14.9 & Wang et al. [8] \\
\hline 19 & Silty clay & 0.5 & 5000 & 5.0 & 15.2 & Wang et al. [8] \\
\hline 20 & Silty clay & 0.5 & 5000 & 5.0 & 18.0 & Wang et al. [8] \\
\hline 21 & Silty clay & 0.5 & 5000 & 5.0 & 18.8 & Wang et al. [8] \\
\hline 22 & Silty clay & 0.5 & 5000 & 5.1 & 15.0 & Wang et al. [8] \\
\hline 23 & Silty clay & 0.5 & 5000 & 5.2 & 11.2 & Wang et al. [8] \\
\hline 24 & Silty clay & 0.5 & 5000 & 5.4 & 10.9 & Wang et al. [8] \\
\hline 25 & Silty clay & 0.5 & 5000 & 5.6 & 10.7 & Wang et al. [8] \\
\hline 26 & Silty clay & 0.5 & 5000 & 5.8 & 10.6 & Wang et al. [8] \\
\hline 27 & Silty clay & 0.5 & 5000 & 6.1 & 9.9 & Wang et al. [8] \\
\hline 28 & Silty clay & 0.5 & 5000 & 6.4 & 9.2 & Wang et al. [8] \\
\hline 29 & Silty clay & 0.5 & 5000 & 6.7 & 9.1 & Wang et al. [8] \\
\hline 30 & Silty clay & 0.5 & 5000 & 7.1 & 8.6 & Wang et al. [8] \\
\hline 31 & Silty clay & 0.5 & 5000 & 7.4 & 8.4 & Wang et al. [8] \\
\hline 32 & Silty clay & 0.5 & 5000 & 7.8 & 7.6 & Wang et al. [8] \\
\hline 33 & Silty clay & 0.5 & 5000 & 8.2 & 6.7 & Wang et al. [8] \\
\hline 34 & Silty clay & 0.5 & 5000 & 8.6 & 6.3 & Wang et al. [8] \\
\hline 35 & Silty clay & 0.5 & 5000 & 9.0 & 3.2 & Wang et al. [8] \\
\hline 36 & Silty clay & 0.5 & 5000 & 9.4 & 2.3 & Wang et al. [8] \\
\hline
\end{tabular}

Note. $R_{\mathrm{c}}$ : radius of jet grouted column; E: Young's modulus of soil; $L_{\mathrm{OA}}$ : distance from column center to target point; $\delta_{\mathrm{A}}$ : measured displacement at the radial direction. 


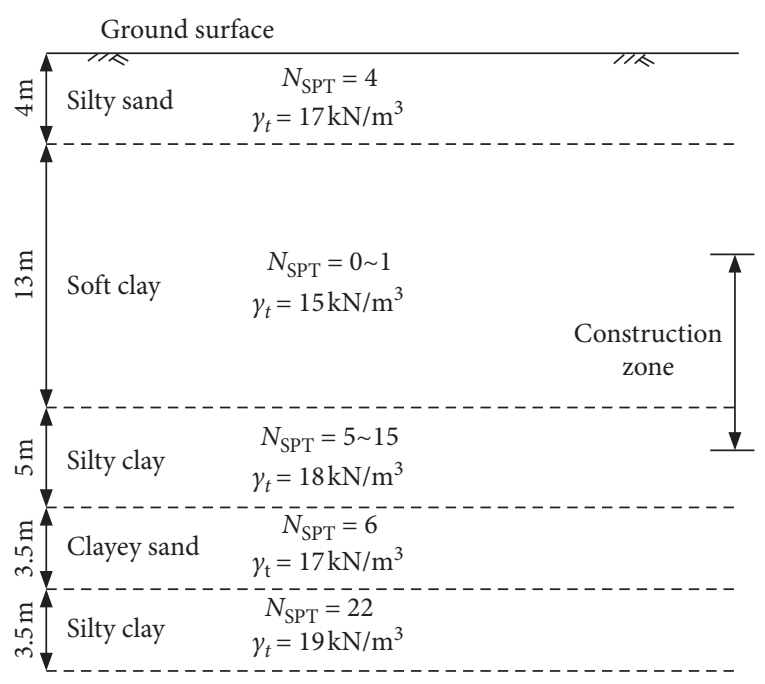

(a)

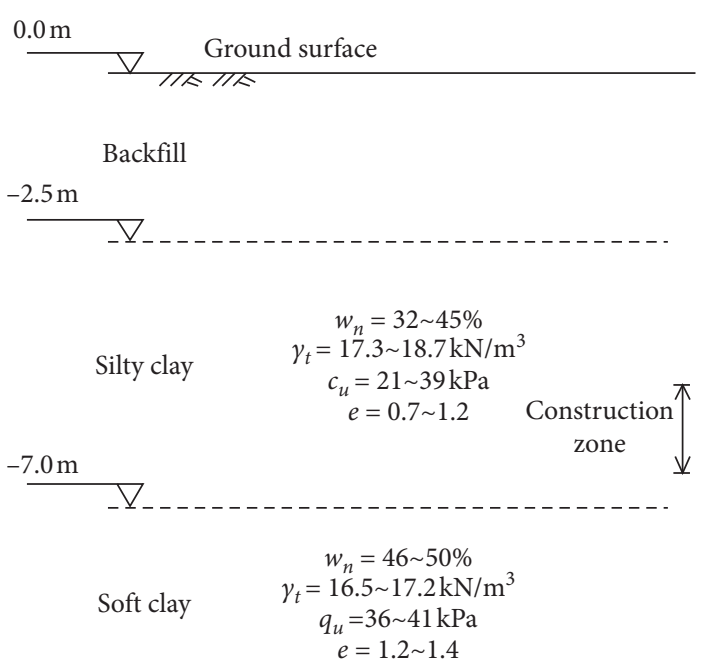

(b)

FIgURE 2: Geotechnical profile and soil conditions for two different cases: (a) case history conducted in soft clay (after [31]); note: $\gamma_{t}=$ unit weight; $N_{\mathrm{SPT}}=$ blow counts of the standard penetration test (SPT); (b) case history conducted in silty clay (after [8]); note: $w_{n}=$ water content; $\gamma_{t}=$ unit weight; $e=$ void ratio; $q_{u}=$ unconfined compressive strength.

independent variables and the dependent variables, and this is different from traditional multiple linear regression (MLR), which is only adopted to obtain linear models. Based on the consideration of the influencing factors on ground displacements and equation (2), the following nonlinear function is proposed to conduct MNLR analysis:

$$
\delta_{A}=\delta_{\text {ref }} \cdot\left(\frac{R_{c}}{0.5}\right)^{a} \cdot\left(\frac{E}{3000}\right)^{b} \cdot\left(\frac{L_{\mathrm{OA}}}{5.0}\right)^{c} \mathrm{~mm},
$$

where $R_{\mathrm{c}}$ is expressed in $\mathrm{m} ; E$ is expressed in $\mathrm{kPa} ; L_{\mathrm{OA}}$ is expressed in $\mathrm{m}$; and $a, b$ and $c$ are empirical coefficients. With such a formulation, $\delta_{\text {ref }}$ has the physical meaning of being the ground displacement produced under the condition having $R_{\mathrm{c}}=0.5 \mathrm{~m}, E=3000 \mathrm{kPa}$, and $L_{\mathrm{OA}}=5.0 \mathrm{~m}$.

MNLR model has been implemented using Statistics and Machine Learning Toolbox in MATLAB 2019a environment with a nonlinear regression code. Based on the running results of the nonlinear regression code, $\delta_{\text {ref }}=40 \mathrm{~mm}$, $a=1.8, b=-1.4$, and $c=-1.7$ are obtained with the best prediction performance.

4.2. Support Vector Regression. The support vector machine (SVM) is a new and efficient artificial intelligence method, which was produced on the basis of statistical learning theory to solve the classification problems at the initial stage, and then, it was developed to deal with the regression problems after introducing the $\varepsilon$-insensitive loss function. SVR can be divided as the linear SVR and the nonlinear SVR. In many cases, it is not suitable using the linear SVR due to the real-world problem is very complex. The principle of SVR technique is introduced briefly in this section.

Taking a series of training data into account $\left\{\left(x_{1}, y_{1}\right)\right.$, $\left.\ldots,\left(x_{n}, y_{n}\right)\right\}, x \in R^{m}, y \in R$, where $x$ is the input parameter, $y$ is the output parameter, $n$ is the number of collected data, $R^{m}$ is the $m$-dimensional vector space, and
$R$ is the one-dimensional vector space. Figure 3 shows the principle of a linear SVR technique, $\mathcal{E}$-insensitive loss function, and slack variables. As can be seen, the shaded area is called as the $\varepsilon$-insensitive tube. For these training data outside of the $\varepsilon$-insensitive tube, they will be given a nonzero slack variable. When the predicted data are inside the $\varepsilon$-insensitive tube, there will be no other differences, which mean that the value of $\varepsilon$-insensitive loss is zero. While the predicted data are outside the $\varepsilon$-insensitive tube, the value of the loss will be equal to be the magnitude of the difference between the estimated data and the tube radius $\varepsilon$ [54]. The $\varepsilon$-insensitive loss function may be determined by the following equation:

$$
L_{\varepsilon}(y)=|y-f(x)|_{\varepsilon}= \begin{cases}0, & \text { if }|y-f(x)| \leq \varepsilon \\ |y-f(x)|-\varepsilon, & \text { otherwise }\end{cases}
$$

where $L_{\varepsilon}(y)$ is the loss function.

The linear function for SVR can be given by the following equation in general:

$$
f(x)=\langle\mathbf{w} \cdot \mathbf{x}\rangle+b,
$$

where $b$ is the bias, $\mathbf{w}$ is the weight vector, and $\langle\mathbf{w} \cdot \mathbf{x}\rangle$ is the inner product of $\mathbf{w}$ and $\mathbf{x}$.

In SVR, there exists a main goal that is to find out a function $f(x)$ that has the ability to minimize the complexity of model $[54,55]$. The aforementioned goal can be achieved by the minimization of the weight vector $(w)$ :

$$
\begin{aligned}
& \operatorname{minimize} \frac{1}{2}\|w\|^{2} \\
& \text { subjected to }\left\{\begin{array}{l}
y_{i}-\left\langle w \cdot x_{i}\right\rangle-b \leq \varepsilon, \\
\left\langle w \cdot x_{i}\right\rangle+b-y_{i} \leq \varepsilon
\end{array}\right.
\end{aligned}
$$




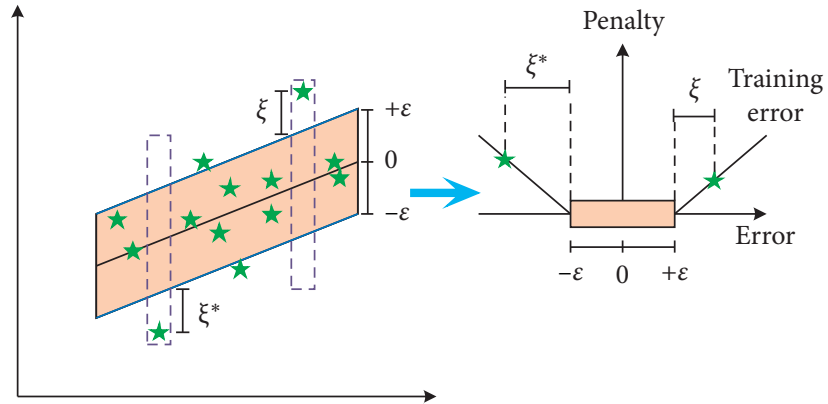

FIgURE 3: Schematic view of a linear SVR technique, $\varepsilon$-insensitive loss function, and slack variables.

However, by the introduction of slack parameters $\xi_{i}, \xi_{i}^{*}$ $(i=1, \ldots, n)$, the estimation error of training data outside the $\mathcal{E}$-insensitive tube could be incorporative. The function of convex optimization could be determined by the following equation:

$$
\begin{aligned}
& \operatorname{minimize} \varphi\left(w, \xi, \xi^{*}\right)=\frac{1}{2}\|w\|^{2}+C \sum_{i=1}^{n}\left(\xi_{i}+\xi_{i}^{*}\right) \\
& \operatorname{subject~to}\left\{\begin{array}{l}
y_{i}-\left\langle\mathbf{w} \cdot \mathbf{x}_{i}\right\rangle-b \leq \varepsilon+\xi_{i}, \\
\left\langle\mathbf{w} \cdot \mathbf{x}_{i}\right\rangle+b-y_{i} \leq \varepsilon+\xi_{i}^{*}, \\
\xi_{i}, \xi_{i}^{*} \geq 0,
\end{array}\right.
\end{aligned}
$$

where $C$ is the penalty parameter that is $>0$. In equation (8), the left term $(1 / 2)\|w\|^{2}$ stands for the structure risk, while the right term $C \sum_{i=1}^{n}\left(\xi_{i}+\xi_{i}^{*}\right)$ stands for the empirical risk. The penalty parameter $C$ determines the trade-off between the term (1/2)\|w $\|^{2}$ and the empirical risk. By introducing a Lagrange function, the function in equation (8) could be transformed as follows:

$$
\begin{aligned}
& \operatorname{maximize} L\left(\alpha^{*}, \alpha\right)=-\varepsilon \sum_{i=1}^{n}\left(\alpha_{i}^{*}+\alpha_{i}\right)+\sum_{i=1}^{n} y_{i}\left(\alpha_{i}^{*}-\alpha_{i}\right)-\frac{1}{2} \sum_{i=1}^{n} \sum_{j=1}^{n}\left(\alpha_{i}^{*}-\alpha_{i}\right)\left(\alpha_{i}^{*}+\alpha_{i}\right)\left(\mathbf{x}_{i} \cdot \mathbf{x}_{j}\right) \\
& \operatorname{maximize}\left\{\begin{array}{l}
\sum_{i=1}^{n}\left(\alpha_{i}^{*}+\alpha_{i}\right) \\
0 \leq \alpha_{i}^{*} \leq C \\
0 \leq \alpha_{i} \leq C
\end{array}\right.
\end{aligned}
$$

where $\alpha^{*}$ and $\alpha$ are Lagrange multipliers and $L\left(\alpha^{*}, \alpha\right)$ is the Lagrange function. When the Lagrange multipliers after optimization are obtained, the regression problem in equation (9) can be expressed as follows:

$$
\begin{gathered}
\mathbf{w}_{0}=\sum_{\text {Support vectors }}\left(\alpha_{i}^{*}+\alpha_{i}\right) x_{i}, \\
b_{0}=-\frac{1}{2} w_{0}\left[\mathbf{x}_{r}+\mathbf{x}_{s}\right] \\
f(x)=\sum_{\text {Support vectors }}\left(\alpha_{i}^{*}-\alpha_{i}\right)\left(\mathbf{x}_{i} \cdot \mathbf{x}\right)+b_{0},
\end{gathered}
$$

where $\mathbf{x}_{r}$ and $\mathbf{x}_{s}$ are the support vectors, $b_{0}$ is the optimum value for the bias, and $w_{0}$ is the optimum value for the weight vector. During the training process of SVR technique, the values of some Lagrange multipliers could become zero, indicating that these training data could be irrelevant for the final regression analysis. Training modes with nonzero Lagrange multipliers are generally called as the support vectors [56]. The abovementioned SVR model is capable of solving the linear regression problems in general.

By introducing a nonlinear kernel function, the following equations can be adopted to solve the nonlinear regression problems: 


$$
\begin{aligned}
f(x) & =\sum_{\text {Support vectors }}\left(\alpha_{i}^{*}-\alpha_{i}\right) K\left(\mathbf{x}_{i} \cdot \mathbf{x}\right)+b_{0}, \\
\mathbf{w}_{0} \cdot \mathbf{x} & =\sum_{\text {Support vectors }}\left(\alpha_{i}^{*}-\alpha_{i}\right) K\left(\mathbf{x}_{i}, \mathbf{x}\right), \\
b_{0} & =\frac{1}{2} \sum_{\text {Support vectors }}\left(\alpha_{i}^{*}-\alpha_{i}\right)\left[K\left(\mathbf{x}_{r}, \mathbf{x}_{i}\right)+K\left(\mathbf{x}_{s}, \mathbf{x}_{i}\right)\right],
\end{aligned}
$$

where $K\left(\mathbf{x}_{i} \cdot \mathbf{x}\right)$ is the kernel function.

$$
K\left(\mathbf{x}_{i} \cdot \mathbf{x}\right)=\left\langle\phi\left(x_{i}\right) \cdot \phi(x)\right\rangle .
$$

By the use of a map $\phi$, the input variables could be mapped onto the feature space. The dot product of $\phi\left(x_{i}\right)$. $\phi(x)$ is calculated by using a linear combination of the training data [57].

In this study, a structure of the SVR technique for prediction of ground displacements is established, as shown in Figure 4. SVR model has been implemented using Statistics and Machine Learning Toolbox in MATLAB 2019a environment with a SVR code. Radial basis kernel function is one of the most widely used kernel functions in SVR and is adopted to analyze the collected data for prediction of ground displacements in this study.

\section{Accuracy of Predicted Values by MNLR and SVR}

In order to evaluate the accuracy of predicted values of ground displacement by MNLR and SVR, five regression indices, namely, correlation coefficient $\left(R^{2}\right)$, mean squared error (MSE), mean absolute error (MAE), mean absolute percentage error (MAPE), and median absolute error (MEDAE), were adopted in this study. These five regression indices can be determined as follows:

$$
\begin{aligned}
\text { correlation coefficient, } R & =\frac{\sum_{i=1}^{n}\left(l_{i}-\overline{l_{i}}\right)\left(m_{i}-\overline{m_{i}}\right)}{\sqrt{\sum_{i=1}^{n}\left(l_{i}-\overline{l_{i}}\right)^{2} \sum_{i=1}^{n}\left(m_{i}-\overline{m_{i}}\right)^{2}}}, \\
\mathrm{MSE} & =\frac{\sum_{i=1}^{n}\left(l_{i}-m_{i}\right)^{2}}{n}, \\
\text { MAPE } & =\frac{100 \%}{n} \times\left[\sum_{i=1}^{n}\left|\frac{l_{i}-m_{i}}{l_{i}}\right|\right], \\
\text { MEDAE } & =\operatorname{median}\left(l_{i}-m_{i}\right),
\end{aligned}
$$$$
\mathrm{MAE}=\frac{1}{n} \sum_{i=1}^{n}\left|l_{i}-m_{i}\right|,
$$

where $l_{i}$ is the observed data, $m_{i}$ is the predicted data, $n$ is the number of adopted data, $\bar{l}_{i}$ is the average value of the observed data, and $\overline{m_{i}}$ is the average value of the predicted data.
Figure 5 shows the prediction performance of ground displacement with MNLR and SVR, in which training data and testing data are included. As can be seen, the prediction performance obtained by using MNLR $\left(\delta_{\text {ref }}=40 \mathrm{~mm}\right.$, $a=1.8, b=-1.4$, and $c=-1.7)$ is better, for training data: $R^{2}=0.96, \mathrm{MSE}=13.32, \mathrm{MAPE}=50.5 \%, \mathrm{MEDAE}=3.2$, and $\mathrm{MAE}=3.3$; for testing data: $R^{2}=0.98, \quad \mathrm{MSE}=14.05$, $\mathrm{MAPE}=12.5 \%, \mathrm{MEDAE}=3.1$, and $\mathrm{MAE}=3.0$. While for the prediction performance obtained by SVR with radial basis function, these five regression indices are listed as follows: for training data: $R^{2}=0.80, \mathrm{MSE}=38.61, \mathrm{MAPE}=35.01 \%$, $\mathrm{MEDAE}=3.0$, and $\mathrm{MAE}=0.84$; for testing data: $R^{2}=0.55$, $\mathrm{MSE}=59.8, \quad \mathrm{MAPE}=21.5 \%, \quad \mathrm{MEDAE}=5.82, \quad$ and $\mathrm{MAE}=5.13$. From these comparison results, it is suggested that the MNLR has a better prediction performance and can be adopted to yield an accurate prediction of the ground displacement caused by installing a jet grouted column.

\section{Design Charts to Estimate Ground Displacement Created by MNLR}

Based on the analysis of prediction performance, it has been proven that the MNLR can be used to yield a good estimation of the ground displacement caused by installing a jet grouted column. In order to increase the application range of this MNLR method, the design charts for predicting the ground displacement caused by installing a jet grouted column for different cases are plotted, as shown in Figure 6, which will make it more convenient for the use of this MNLR method in engineering practice. As can be seen in this figure, the column radius $R_{\mathrm{c}}$ varies from $0.25 \mathrm{~m}$ to $1.25 \mathrm{~m}$, and Young's modulus $E$ is within the range of $2500 \mathrm{kPa}$ to $30000 \mathrm{kPa}$, while the distance from column center to target point $L_{\mathrm{OA}}$ changes from $3 \mathrm{~m}$ to $18 \mathrm{~m}$. These design charts basically cover the most situations that can be encountered in engineering practice. Considering the construction issues and soil conditions in engineering site, the column radius can be estimated using the existed method [39, 41-43] firstly, and then, the practicing engineers can get a quick prediction of the ground displacement caused by installing a jet grouted column based on the design charts proposed in this paper. In engineering practice, it is always encountered that multiple rows of jet grouted columns are installed. For such cases, based on the assumption of the principle of superposition, the ground displacements induced by installing a row of columns can be determined by the sum of the displacement caused by each individual column, as shown in the following equation and Figure 7:

$$
\delta_{\text {Asum }}=\sum_{i=1}^{n} \delta_{\mathrm{A} i},
$$

where $\delta_{\text {Asum }}$ is the ground displacements induced by installing a row of columns; $i$ stands for the number of the jet grouted column being installed; and $\delta_{\mathrm{A} i}$ is the displacement caused by installation of column $i$, which can be estimated by the design charts in this study. 


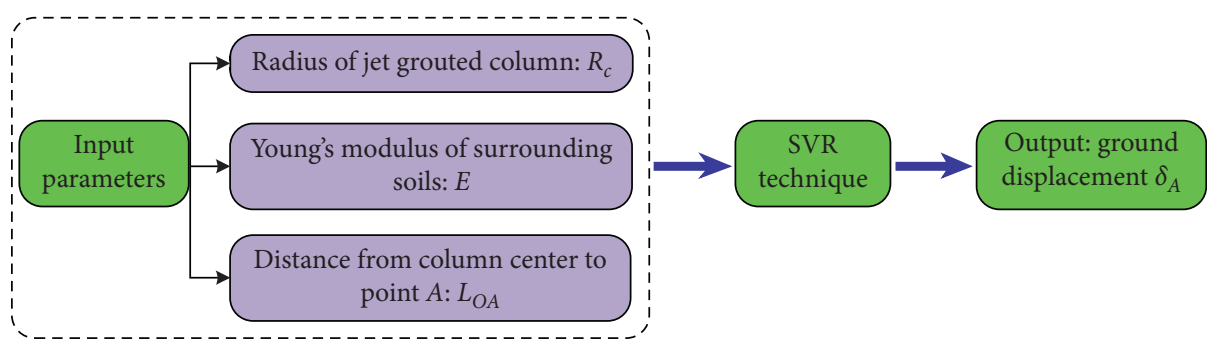

Figure 4: Prediction structure of the SVR technique in this study.

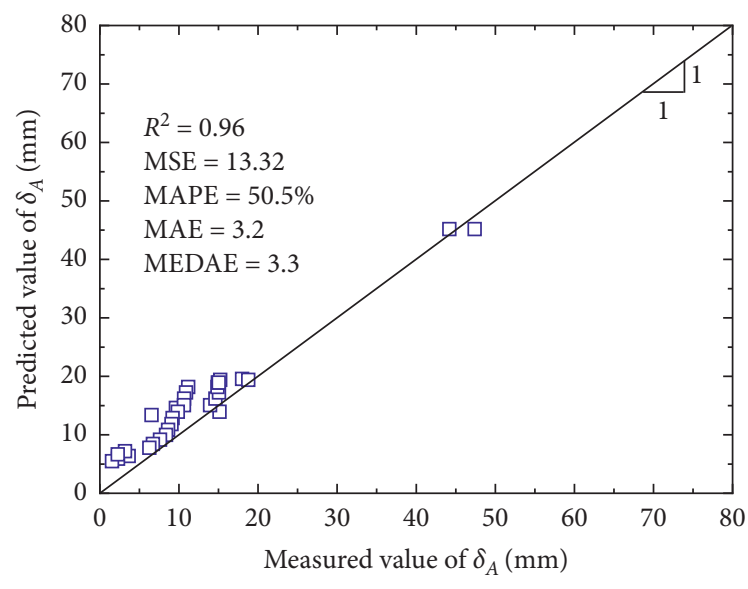

$\square$ Training data

(a)

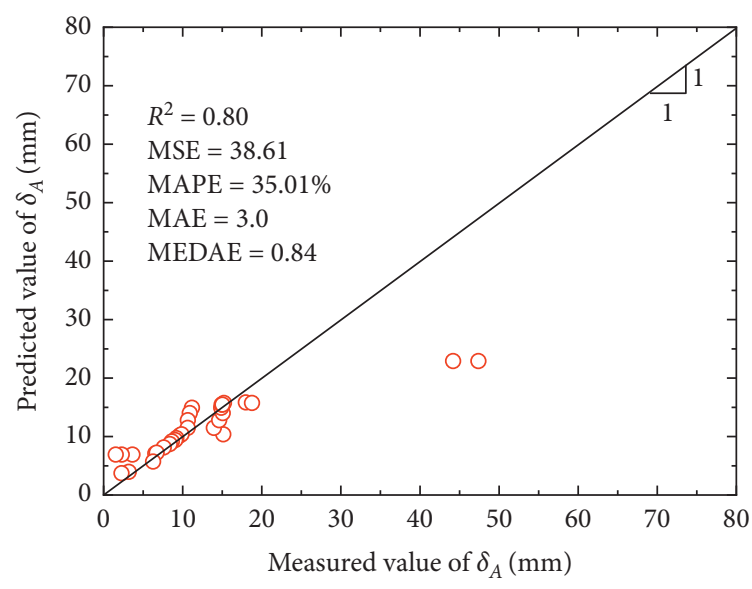

○ Training data

(c)

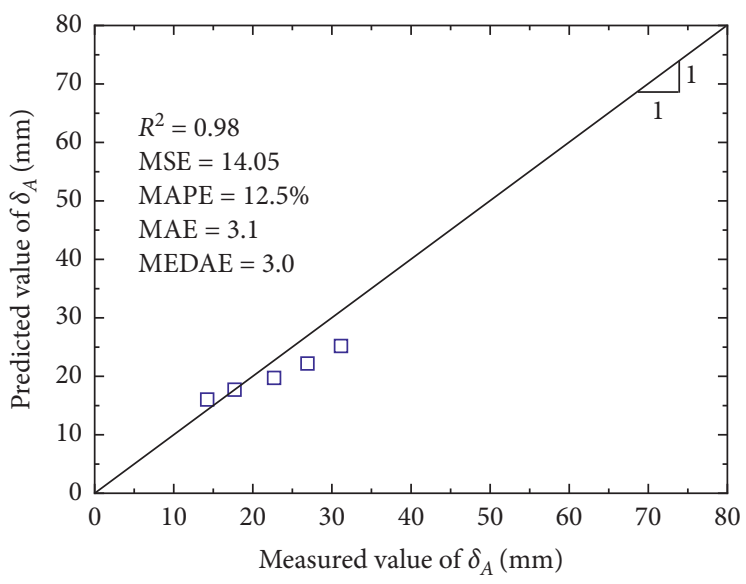

๑ Testing data

(b)

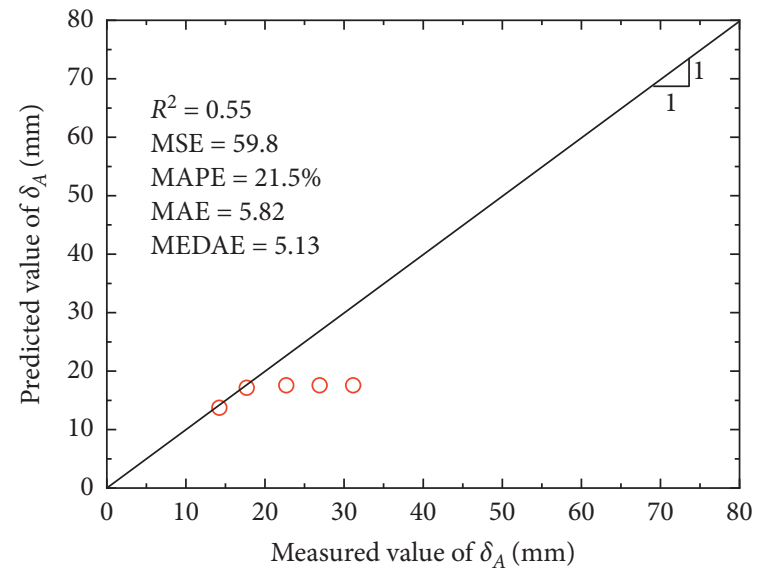

○ Testing data

(d)

FIGURE 5: Prediction performance of ground displacement with different methods: (a) MNLR model (training); (b) MNLR model (testing); (c) SVR model (training); (d) SVR model (testing). 

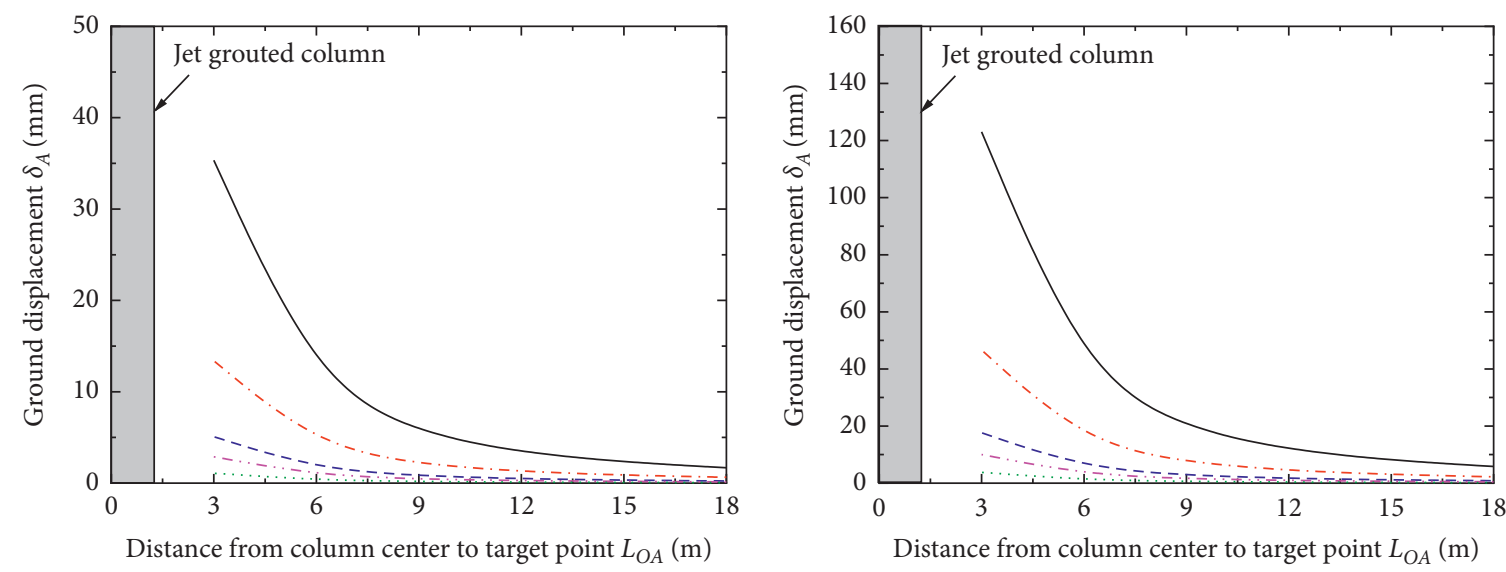

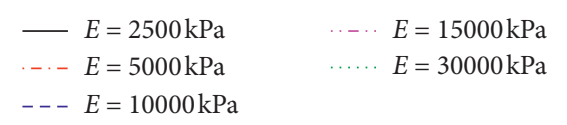

(a)

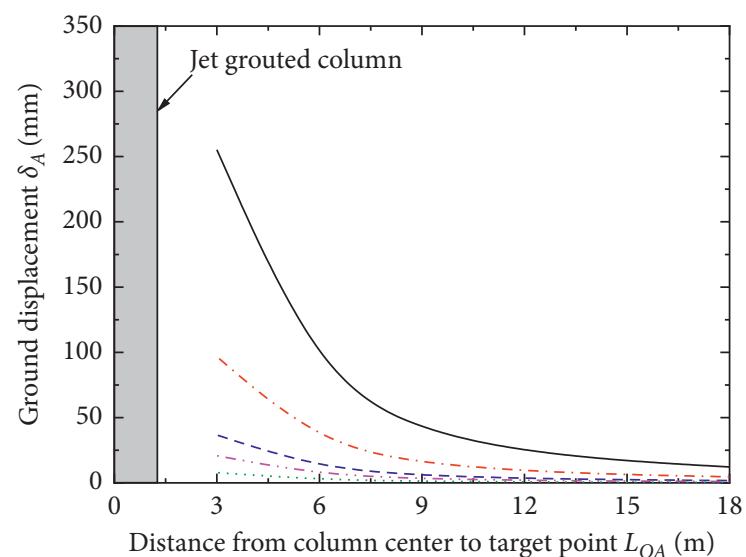

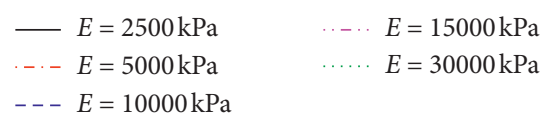

(b)

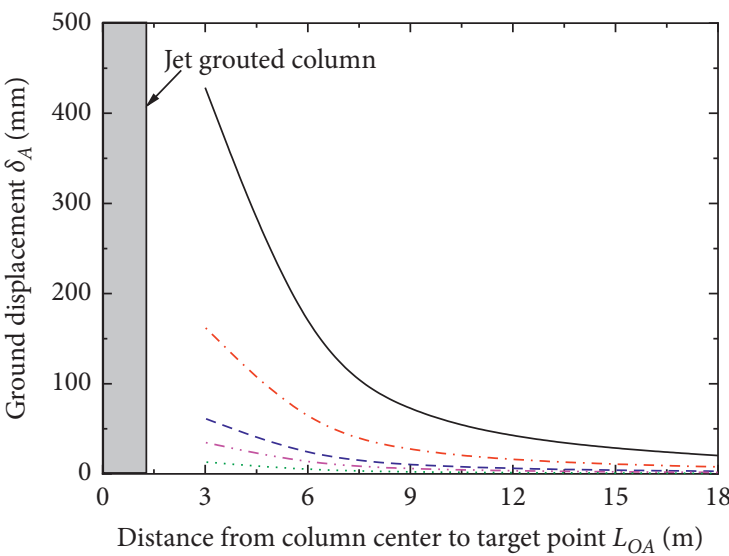

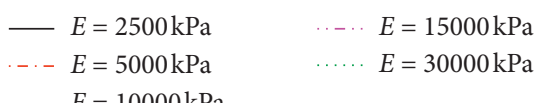

$E=10000 \mathrm{kPa}$

(d)

(c)

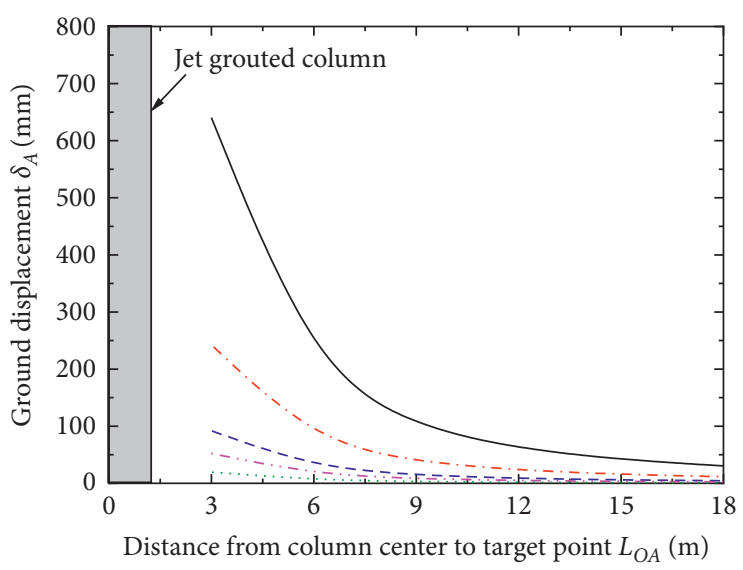

$$
\begin{aligned}
& -E=2500 \mathrm{kPa} \\
& \text { …E } E=15000 \mathrm{kPa} \\
& \text {-. } E=5000 \mathrm{kPa} \\
& \text { … } E=30000 \mathrm{kPa} \\
& \text { - - } E=10000 \mathrm{kPa}
\end{aligned}
$$

(e)

Figure 6: Design charts for estimating ground displacement caused by installing a jet grouted column: (a) $R_{\mathrm{c}}=0.25 \mathrm{~m}$; (b) $R_{\mathrm{c}}=0.50 \mathrm{~m}$; (c) $R_{\mathrm{c}}=0.75 \mathrm{~m}$; (d) $R_{\mathrm{c}}=1.00 \mathrm{~m}$; (e) $R_{\mathrm{c}}=1.25 \mathrm{~m}$. 


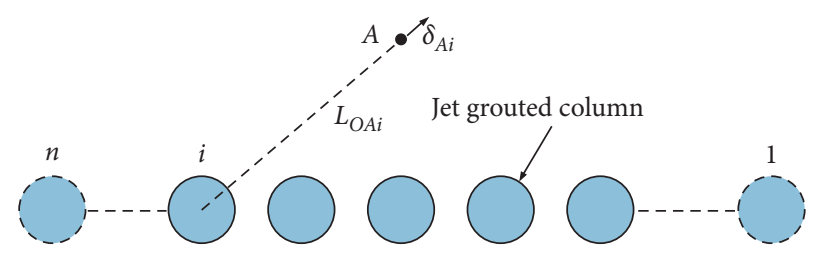

FIGURE 7: Illustration of ground displacements induced by installing a row of columns (after [31]).

\section{Conclusions}

Predicting the ground displacements caused by installing jet grouted columns is an important issue in the design stage of jet grouting, and large error in prediction may induce harmful results in engineering practice. Based upon the machine learning methods, prediction of the ground displacement caused during jet grouting is analyzed and discussed in this study, and the conclusions can be drawn as follows:

(1) The factors influencing the ground displacements can be divided as jetting parameters, soil properties, and distance to target point. The column radius $\left(R_{\mathrm{c}}\right)$, Young's modulus $(E)$, and distance from column center to target point $\left(L_{\mathrm{OA}}\right)$ are selected as the input parameters, while the displacement of target point A at the radial direction $\left(\delta_{\mathrm{A}}\right)$ is taken as the output parameter.

(2) The prediction approaches are established, respectively, based on MNLR and SVR. A nonlinear equation to express the relationship between the input parameters $\left(R_{\mathrm{c}}, E\right.$, and $\left.L_{\mathrm{OA}}\right)$ and the output parameter $\left(\delta_{\mathrm{A}}\right)$ is proposed in this study. Comparisons results on prediction performance of ground displacements indicate that the MNLR-based approach has a better prediction effect.

(3) Using the MNLR-based approach, the design charts for predicting the ground displacement induced by installation of jet grouted columns are created to increase the convenience for the use of the MNLR model in engineering practice. Based on the proposed design charts, the practicing engineers can get a quick estimation of the ground displacements caused by installing jet grouted columns.

\section{Data Availability}

The data used to support the findings of this research work are included within the article.

\section{Conflicts of Interest}

The authors declare that there are no conflicts of interest.

\section{Acknowledgments}

The research described in this study was funded by the project supported by the Natural Science Basic Research Plan in Shaanxi Province of China (Program no. 2019JQ-
114), the National Nature Science Foundation of China (NSFC) (Grant nos. 41702287 and 41807245), and the Fundamental Research Funds for the Central Universities (Grant no. 300102218517). These financial supports are gratefully acknowledged.

\section{References}

[1] X. Bian, Y.-J. Cui, and X.-Z. Li, "Voids effect on the swelling behaviour of compacted bentonite," Géotechnique, vol. 69, no. 7, pp. 593-605, 2019.

[2] X. Bian, Y.-J. Cui, L.-L. Zeng, and X.-Z. Li, "Swelling behavior of compacted bentonite with the presence of rock fracture," Engineering Geology, vol. 254, pp. 25-33, 2019.

[3] S. Coulter and C. D. Martin, "Effect of jet-grouting on surface settlements above the Aeschertunnel, Switzerland," Tunnelling and Underground Space Technology, vol. 21, no. 5, pp. 542-553, 2006.

[4] S.-L. Shen, Z.-F. Wang, W.-J. Sun, L.-B. Wang, and S. Horpibulsuk, "A field trial of horizontal jet grouting using the composite-pipe method in the soft deposits of Shanghai," Tunnelling and Underground Space Technology, vol. 35, pp. 142-151, 2013.

[5] S.-L. Shen, Z.-F. Wang, S. Horpibulsuk, and Y.-H. Kim, "Jet grouting with a newly developed technology: the twin-jet method," Engineering Geology, vol. 152, no. 1, pp. 87-95, 2013.

[6] G. N. Karahan and O. Sivrikaya, "Designing singular jet grouting column for sandy soils," Environmental Earth Sciences, vol. 77, no. 12, p. 448, 2018.

[7] Z.-F. Wang, W.-C. Cheng, and Y.-Q. Wang, "Investigation into geohazards during urbanization process of Xi'an, China," Natural Hazards, vol. 92, no. 3, pp. 1937-1953, 2018.

[8] Z. F. Wang, J. S. Shen, and W. C. Cheng, "Simple method to predict ground displacements caused by installing horizontal jet-grouting columns," Mathematical Problems in Engineering, vol. 2018, Article ID 1897394, 11 pages, 2018.

[9] C. Toraldo, G. Modoni, M. Ochmański, and P. Croce, “The characteristic strength of jet-grouted material," Géotechnique, vol. 68, no. 3, pp. 262-279, 2018.

[10] Y.-Q. Wang, Z.-F. Wang, and W.-C. Cheng, "A review on land subsidence caused by groundwater withdrawal in Xi'an, China," Bulletin of Engineering Geology and the Environment, vol. 78, no. 4, pp. 2851-2863, 2019.

[11] Z.-F. Wang, S.-L. Shen, and G. Modoni, "Enhancing discharge of spoil to mitigate disturbance induced by horizontal jet grouting in clayey soil: theoretical model and application," Computers and Geotechnics, vol. 111, pp. 222-228, 2019.

[12] Y. Wei, X. Gao, F. Wang, and Y. Zhong, "Nonlinear strain distribution in a field-instrumented concrete pavement slab in response to environmental effects," Road Materials and Pavement Design, vol. 20, no. 2, pp. 367-380, 2019.

[13] Y. Wei, Z. Wu, X. Yao, and X. Gao, "Quantifying effect of later curing on pores of paste subject to early age freeze thaw cycles by different techniques," Journal of Materials in Civil Engineering, vol. 31, no. 8, Article ID 04019153, 2019.

[14] G. Modoni and J. Bzówka, "Analysis of foundations reinforced with jet grouting," Journal of Geotechnical and Geoenvironmental Engineering, vol. 138, no. 12, pp. 1442-1454, 2012.

[15] M. Ochmański, G. Modoni, and J. Bzòwka, "Numerical analysis of tunnelling with jet-grouted canopy," Soils and Foundations, vol. 55, no. 5, pp. 929-942, 2015.

[16] Q. L. Cui, H. N. Wu, S. L. Shen, Z. Y. Yin, and S. Horpibulsuk, "Protection of neighbour buildings due to construction of 
shield tunnel in mixed ground with sand over weathered granite," Environmental Earth Sciences, vol. 75, no. 6, p. 458, 2016.

[17] G. Modoni, A. Flora, S. Lirer, M. Ochmański, and P. Croce, "Design of jet grouted excavation bottom plugs," Journal of Geotechnical and Geoenvironmental Engineering, vol. 142, no. 7, Article ID 04016018, 2016.

[18] C. E. Ho, "Groundwater management for sustainable underground subway development in Manhattan, New York City," in Proceedings of the 1st Geo-Chicago Conference: Sustainability and Resiliency in Geotechnical Engineering, Geo-Chicago, Geotechnical Special Publication No. 269, American Society of Civil Engineers (ASCE) Press, pp. 663-672, Chicago, IL, USA, August 2016.

[19] J. Lai, H. Fan, J. Chen, J. Qiu, and K. Wang, "Blasting vibration monitoring of undercrossing railway tunnel using wireless sensor network," International Journal of Distributed Sensor Networks, vol. 11, no. 6, Article ID 703980, 2015.

[20] J. Qiu, Y. Xie, H. Fan, Z. Wang, and Y. Zhang, "Centrifuge modelling of twin-tunnelling induced ground movements in loess strata," Arabian Journal of Geosciences, vol. 10, no. 22, p. 493, 2017.

[21] J. X. Lai, S. Y. He, J. L. Qiu et al., "Characteristics of seismic disasters and aseismic measures of tunnels in Wenchuan earthquake," Environmental Earth Science, vol. 76, no. 2, p. 94, 2017.

[22] J. L. Qiu, H. Q. Liu, J. X. Lai, H. P. Lai, J. X. Chen, and $\mathrm{K}$. Wang, "Investigating the long-term settlement of a tunnel built over improved loessial foundation soil using jet grouting technique," Journal of Performance Constructed Facilities, vol. 32, no. 5, Article ID 04018066, 2018.

[23] W.-C. Cheng, J. C. Ni, A. Arulrajah, and H.-W. Huang, "A simple approach for characterising tunnel bore conditions based upon pipe-jacking data," Tunnelling and Underground Space Technology, vol. 71, pp. 494-504, 2018.

[24] W.-C. Cheng, J. C. Ni, H.-W. Huang, J. S. Shen, and J. S. Shen, "The use of tunnelling parameters and spoil characteristics to assess soil types: a case study from alluvial deposits at a pipejacking project site," Bulletin of Engineering Geology and the Environment, vol. 78, no. 4, pp. 2933-2942, 2019.

[25] W.-C. Cheng, L. Wang, Z.-F. Xue, J. C. Ni, M. M. Rahman, and A. Arulrajah, "Lubrication performance of pipejacking in soft alluvial deposits," Tunnelling and Underground Space Technology, vol. 91, Article ID 102991, 2019.

[26] W.-C. Cheng, G. Li, N. Liu, J. Xu, and S. Horpibulsuk, "Recent massive incidents for subway construction in soft alluvial deposits of Taiwan: a review," Tunnelling and Underground Space Technology, vol. 96, Article ID 103178, 2020.

[27] X. Bian, Y.-J. Cui, L.-L. Zeng, and X.-Z. Li, "State of compacted bentonite inside a fractured granite cylinder after infiltration," Applied Clay Science, vol. 186, Article ID 105438, 2020.

[28] P. Jamsawang, P. Voottipruex, P. Boathong, W. Mairaing, and S. Horpibulsuk, "Three-dimensional numerical investigation on lateral movement and factor of safety of slopes stabilized with deep cement mixing column rows," Engineering Geology, vol. 188, pp. 159-167, 2015.

[29] P. Jamsawang, S. Jamnam, P. Jongpradist, P. Tanseng, and S. Horpibulsuk, "Numerical analysis of lateral movements and strut forces in deep cement mixing walls with top-down construction in soft clay," Computers and Geotechnics, vol. 88, pp. 174-181, 2017.

[30] J. Han, F. Wang, M. Al-Naddaf, and C. Xu, "Progressive development of two-dimensional soil arching with displacement," International Journal of Geomechanics, vol. 17, no. 12, Article ID 04017112, 2017.

[31] S. L. Shen, Z. F. Wang, and W. C. Cheng, "Estimation of lateral displacement induced by jet grouting in clayey soils," Géotechnique, vol. 67, no. 7, pp. 621-630, 2017.

[32] Z. F. Wang, W. C. Cheng, and Y. Q. Wang, "Simple method to predict settlement of composite foundation under embankment," International Journal of Geomechanics, vol. 18, no. 12, Article ID 04018158, 2018.

[33] J. C. Ni and W.-C. Cheng, "Quality control of double fluid jet grouting below groundwater table: case history," Soils and Foundations, vol. 54, no. 6, pp. 1039-1053, 2014.

[34] P. G. A. Njock, J. Chen, G. Modoni, A. Arulrajah, and Y. H. Kim, "A review of jet grouting practice and development," Arabian Journal of Geosciences, vol. 11, no. 16, p. 459, 2018.

[35] P. G. A. Njock, J. S. Shen, G. Modoni, and A. Arulrajah, "Recent advances in horizontal jet grouting (HJG): an overview," Arabian Journal for Science and Engineering, vol. 43, no. 4, pp. 1543-1560, 2018.

[36] Z.-F. Wang, S.-L. Shen, C.-E. Ho, and Y.-H. Kim, "Investigation of field-installation effects of horizontal twin-jet grouting in Shanghai soft soil deposits," Canadian Geotechnical Journal, vol. 50, no. 3, pp. 288-297, 2013.

[37] Z.-F. Wang, S.-L. Shen, C.-E. Ho, and Y.-S. Xu, "Jet grouting for mitigation of installation disturbance," Proceedings of the Institution of Civil Engineers-Geotechnical Engineering, vol. 167, no. 6, pp. 526-536, 2014.

[38] Z.-F. Wang, S.-L. Shen, G. Modoni, and A. Zhou, "Excess pore water pressure caused by the installation of jet grouting columns in clay," Computers and Geotechnics, vol. 125, Article ID 103667, 2020.

[39] G. Modoni, P. Croce, and L. Mongiovì, "Theoretical modelling of jet grouting," Géotechnique, vol. 56, no. 5, pp. 335-347, 2006.

[40] C. E. Ho, "Fluid-soil interaction model for jet grouting," in Proceedings of the Grouting for Ground Improvement: Innovative Concepts and Applications, Geotechnical Special Publication No. 168, American Society of Civil Engineers (ASCE) Press, pp. 1-10, Denver, CO, USA, February 2007.

[41] A. Flora, G. Modoni, S. Lirer, and P. Croce, "The diameter of single, double and triple fluid jet grouting columns: prediction method and field trial results," Géotechnique, vol. 63, no. 11, pp. 934-945, 2013.

[42] S.-L. Shen, Z.-F. Wang, J. Yang, and C.-E. Ho, "Generalized approach for prediction of jet grout column diameter," Journal of Geotechnical and Geoenvironmental Engineering, vol. 139, no. 12, pp. 2060-2069, 2013.

[43] M. Ochmański, G. Modoni, and J. Bzòwka, "Prediction of the diameter of jet grouting columns with artificial neural networks," Soils and Foundations, vol. 55, no. 2, pp. 425-436, 2015.

[44] S.-L. Shen, P. G. Atangana Njock, A. Zhou, and H.-M. Lyu, "Dynamic prediction of jet grouted column diameter in soft soil using Bi-LSTM deep learning," Acta Geotechnica, 2020.

[45] A. Verruijt, "Deformations of an elastic half plane with a circular cavity," International Journal of Solids and Structures, vol. 35, no. 21, pp. 2795-2804, 1998.

[46] A. T. C. Goh and S. H. Goh, "Support vector machines: their use in geotechnical engineering as illustrated using seismic liquefaction data," Computers and Geotechnics, vol. 34, no. 5, pp. 410-421, 2007.

[47] P. Samui, T. G. Sitharam, and P. U. Kurup, "OCR prediction using support vector machine based on piezocone data," 
Journal of Geotechnical and Geoenvironmental Engineering, vol. 134, no. 6, pp. 894-898, 2008.

[48] S. K. Das, P. Samui, and A. K. Sabat, "Prediction of field hydraulic conductivity of clay liners using an artificial neural network and support vector machine," International Journal of Geomechanics, vol. 12, no. 5, pp. 606-611, 2012.

[49] H. Güllü, "A new prediction method for the rheological behavior of grout with bottom ash for jet grouting columns," Soils and Foundations, vol. 57, no. 3, pp. 384-396, 2017.

[50] J. Tinoco, A. Gomes Correia, and P. Cortez, "Jet grouting column diameter prediction based on a data-driven approach," European Journal of Environmental and Civil Engineering, vol. 22, no. 3, pp. 338-358, 2018.

[51] İ. F. Öge and M. Çırak, "Relating rock mass properties with Lugeon value using multiple regression and nonlinear tools in an underground mine site," Bulletin of Engineering Geology and the Environment, vol. 78, no. 2, pp. 1113-1126, 2019.

[52] S. Shiripour, I. Mahdavi, and N. Mahdavi-Amiri, "A nonlinear model for a capacitated stochastic transportation network using multiple linear regression," International Journal of Management Science and Engineering Management, vol. 11, no. 4, pp. 252-261, 2016.

[53] J. Xu, X. Zhao, Y. Yu, T. Xie, G. Yang, and J. Xue, "Parametric sensitivity analysis and modelling of mechanical properties of normal- and high-strength recycled aggregate concrete using grey theory, multiple nonlinear regression and artificial neural networks," Construction and Building Materials, vol. 211, pp. 479-491, 2019.

[54] P. Debnath and A. K. Dey, "Prediction of bearing capacity of geogrid-reinforced stone columns using support vector regression," International Journal of Geomechanics, vol. 18, no. 2, Article ID 04017147, 2018.

[55] C. Cortes and V. Vapnik, "Support-vector networks," Machine Learning, vol. 20, no. 3, pp. 273-297, 1995.

[56] Y. B. Dibike, S. Velickov, D. Solomatine, and M. B. Abbott, "Model induction with support vector machines: introduction and applications," Journal of Computing in Civil Engineering, vol. 15, no. 3, pp. 208-216, 2001.

[57] P. Samui, "Support vector machine applied to settlement of shallow foundations on cohesionless soils," Computers and Geotechnics, vol. 35, no. 3, pp. 419-427, 2008. 